\title{
Applying distance-to-target weighing methodology to evaluate the environmental performance of bio-based energy, fuels, and materials
}

\author{
Martin Weiss ${ }^{\mathrm{a}, *}$, Martin Patel ${ }^{\mathrm{a}}$, \\ Hermann Heilmeier ${ }^{b}$, Stefan Bringezu ${ }^{c}$ \\ ${ }^{a}$ Utrecht University, Department of Science, Technology and Society (STS), Copernicus Institute, \\ Heidelberglaan 2, NL-3584 CH Utrecht, The Netherlands \\ ${ }^{\mathrm{b}}$ TU Bergakademie Freiberg, Interdisciplinary Ecological Centre, Biology/Ecology Unit, \\ Leipziger Strasse 29, D-09599 Freiberg, Germany \\ ${ }^{\mathrm{c}}$ Wuppertal Institute, Research Unit on Material Flows and Resource Management, \\ Döppersberg 19, D-42103 Wuppertal, Germany
}

Received 12 January 2006; received in revised form 15 June 2006; accepted 15 June 2006 Available online 14 August 2006

\begin{abstract}
The enhanced use of biomass for the production of energy, fuels, and materials is one of the key strategies towards sustainable production and consumption. Various life cycle assessment (LCA) studies demonstrate the great potential of bio-based products to reduce both the consumption of non-renewable energy resources and greenhouse gas emissions. However, the production of biomass requires agricultural land and is often associated with adverse environmental effects such as eutrophication of surface and ground water. Decision making in favor of or against bio-based and conventional fossil product alternatives therefore often requires weighing of environmental impacts. In this article, we apply distance-to-target weighing methodology to aggregate LCA results obtained in four different environmental impact categories (i.e., non-renewable energy consumption, global warming potential, eutrophication potential, and acidification potential) to one environmental index. We include 45 bio- and fossil-based product pairs in our analysis, which we conduct for Germany. The resulting environmental indices for all product pairs analyzed range from -19.7 to +0.2 with negative values indicating overall environmental benefits of bio-based products. Except for three options of packaging materials made from wheat and cornstarch, all bio-based products (including energy, fuels,
\end{abstract}

\footnotetext{
* Corresponding author. Tel.: +31 30253 5144; fax: +31 302537601 .

E-mail address: m.weiss@ chem.uu.nl (M. Weiss).
} 
and materials) score better than their fossil counterparts. Comparing the median values for the three options of biomass utilization reveals that bio-energy $(-1.2)$ and bio-materials $(-1.0)$ offer significantly higher environmental benefits than bio-fuels $(-0.3)$. The results of this study reflect, however, subjective value judgments due to the weighing methodology applied. Given the uncertainties and controversies associated not only with distance-to-target methodologies in particular but also with weighing approaches in general, the authors strongly recommend using weighing for decision finding only as a supplementary tool separately from standardized LCA methodology.

(c) 2006 Elsevier B.V. All rights reserved.

Keywords: Biomass; Life cycle assessment; Environmental impact categories; Distance-to-target weighing

\section{Introduction}

The application of biomass ${ }^{1}$ used to substitute fossil resources for the production of energy, fuels, and materials is a widely accepted strategy towards sustainable development. Many studies have proven the great potential of bio-based energy, fuels and materials for reducing both non-renewable energy consumption and fossil carbon dioxide $\left(\mathrm{CO}_{2}\right)$ emissions compared to their fossil counterparts (e.g., Dornburg et al., 2004; Patel et al., 2003; Reinhardt and Zemanek, 2000). However, production and processing of biomass is also associated with negative environmental impacts. Agricultural biomass production might cause adverse environmental effects such as soil erosion, eutrophication of ground and surface waters, or fragmentation of habitats. Cultivation, extraction and processing of biomass consume fossil fuels and involve the application of artificial fertilizers and hazardous chemicals. In view of current efforts to produce bio-energy, -fuels, and -materials in bulk, the availability of farmland for non-food purposes deserves special attention. In the medium and long term, agricultural land available for biomass production might become scarce in Western Europe also due to demand for other purposes such as infrastructure, housing, recreation, or nature conservation. In the year 2000, the land use equivalent of the total domestic consumption of agricultural goods in the European Union (EU) already exceeded the actual agricultural land used within the EU by nearly one fifth (Bringezu and Steger, 2005). Thus, additional land use and biomass production for non-food purposes will have to be most efficient in order to serve the various purposes, including the relief of environmental pressure. It is, therefore, important to quantify and evaluate all the advantages and disadvantages associated with the use of biomass along the whole life cycle of biobased products. To this end, life cycle assessment (LCA) has been applied as a common tool by many authors (e.g., Müller-Sämann et al., 2002; Corbière-Nicollier et al., 2001; Reinhardt et al., 2000; Dinkel et al., 1996). The results of these studies show a relatively uniform picture: while bio-based energy, fuels, and materials often yield better results with respect to non-renewable energy consumption and greenhouse gas emissions, fossil-based products generally score better regarding eutrophication, acidification, and stratospheric ozone depletion. These results call for a thorough comparison and evaluation of all envi-

\footnotetext{
${ }^{1}$ In this article, we define biomass as the sum of all organic products from agriculture and forestry, which are used for non-food applications.
} 
ronmental impacts associated with both bio-based and conventional products in order not to compromise environmental benefits with major environmental drawbacks.

Comparing and evaluating different environmental impacts is, however, by no means straightforward because scientific knowledge and subjective value judgments have to be combined in order to develop transparent evaluation criteria. The decision process in favor of or against comparable product alternatives often involves weighing different environmental impact categories within a sustainability framework (Kaenzig et al., 2004). Weighing always implies value judgment and is therefore to some extent subjective. For this reason, the ISO standard on life cycle impact assessment (LCIA) recommends "weighing [...] shall not be used [in LCA] for comparative assertions disclosed to the public" (CEN, 2000).

Weighing is generally seen as a task for economic, environmental and political decision makers. However, these decision makers often lack a rationale for decision finding. Therefore, various methods for weighing environmental impacts were developed within the LCA community. ${ }^{2}$ Weighing usually results in so-called 'weighing factors', which express the contribution of one particular environmental impact category to the total environmental impact of a particular product (Finnveden et al., 2002). Within a large variety of different weighing methods such as proxy, technology abatement, monetization, and panel approaches, distance-to-target methodology ${ }^{3}$ can be applied to evaluate the various environmental impacts of bio-based and conventional products. Distance-to-target approaches evaluate different environmental impact categories depending on the distance between a current level of environmental pollution and a future environmental target value.

In this article we apply distance-to-target weighing methodology to evaluate and compare the environmental performance of energy, fuels, and materials produced from biomass and conventional fossil resources. The distance-to-target weighing methodology applied focuses thereby on the environmental situation in Germany. This country is chosen because (i) scientific studies are available proposing environmental standards and sustainability targets for several environmental impacts, (ii) there is a huge interest in enhanced biomass utilization in Germany, and (iii) there is still strong controversy among stakeholders, scientists and politicians regarding the question, which options of biomass utilization (production of energy, fuels, or materials) should be favored in the future.

The research presented in this article is based on earlier comparisons of bio-based and conventional products as published by Weiss et al. (2004) and Weiss and Patel (in press). The purpose of this article is, therefore, not only to assess the relative environmental impacts of bio-based products with respect to four separate environmental impact categories but (i) to apply distance-to-target methodology in order to analyze the environmental performance of bio-based products by using a new technique in life cycle assessment and (ii) to study the effect of the applied weighing methodology on the outcome and interpretation of the analyzed life cycle assessment studies. To our knowledge, such an analysis has not been performed so far. By applying distance-to-target weighing methodology, we furthermore present a case study for one possible tool used for assisting the decision making process

\footnotetext{
${ }^{2}$ For a comprehensive review of alternative weighing methodologies (see Finnveden et al., 2002).

3 The distance-to-target methodology applied here includes two steps, impact normalization and weighing. For reasons of simplicity we refer in this article to distance-to-target weighing when describing the applied normalization and weighing methodology (see Section 2.2).
} 
regarding the environmental performance of bio-based energy, fuels and materials, and their conventional counterparts.

Following the introduction, we give a detailed description of the methodology applied to compare the environmental performance of bio-based and conventional products (Section 2). We show the most important results of our research in Section 3. Special attention is, thereby, paid to the question of which alternative for biomass use (production of energy, fuels, or materials) is generally most favorable from an environmental point of view, as far as generalized statements can be made. The results obtained and methodologies applied in this article are critically discussed in Section 4. In the final Section 5, we draw conclusions and discuss the relevance of our findings for bio-based energy, fuels, and materials.

\section{Methodology}

\subsection{Comparison of life cycle assessment publications}

In this article, we analyze the results of eleven LCA publications, which cover a total of 45 bio- and fossil-based product pairs (including energy, fuels, and materials) (CorbièreNicollier et al., 2001; Diener and Siehler, 1999; Dinkel et al., 1996; Dinkel and Waldeck, 1999; Gärtner et al., 2002; Müller-Sämann et al., 2002; Reinhardt et al., 2000; Reinhardt and Gärtner, 2003; Reinhardt and Zemanek, 2000; Wötzel et al., 1999; Würdinger et al., 2002). All selected studies compare bio-based energy, fuels, and materials with their conventional fossil-based counterparts on a cradle-to-grave basis, i.e., they cover the entire process chain from biomass production or the extraction of fossil resources, via processing of intermediate and final products, up to the disposal of wastes. One important criterion for the selection of the LCA publications for use in this analysis was that the respective studies assess more environmental impacts than non-renewable energy consumption and fossil $\mathrm{CO}_{2}$ emissions alone.

The analyzed LCA publications refer to the situation in Europe and represent the state of technology until the year 2002. The LCA publications analyzed in this article differ considerably regarding the amount of background data published and the detail of explanations given on methodology and results. Furthermore, the LCA studies vary from each other regarding assumptions made on agricultural yields, treatment of agricultural residues, allocation methods for high-value by-products, and waste treatment options. We did not correct for all of these differences, instead, we compared bio-based and fossil products based on the assumptions made in each respective LCA publication. ${ }^{4}$ The most important assumptions made in the LCA publications analyzed are described in greater detail in Weiss and Patel (in press).

From the various environmental impacts considered in the LCA publications, we select four categories for our analysis in this article. The selection criteria are based on data availability and the quality of published background information. In this article we evaluate the environmental performance of 45 product pairs made from renewable and fossil resources

\footnotetext{
4 This approach differs from the analysis done by Dornburg et al. (2004). There, the regional and producerspecific LCA data are harmonized by (i) assuming identical average yields for agricultural crops, by (ii) assuming waste incineration without energy recovery as the only waste treatment option, and by (iii) using life cycle data for fossil-based polymers from one single source, i.e., APME (1999).
} 
by means of the following four environmental impact categories:

(i) non-renewable energy consumption ${ }^{5}$;

(ii) global warming potential;

(iii) eutrophication potential;

(iv) acidification potential.

We assume that the carbon dioxide originating from biomass is equivalent to the amount, which was previously withdrawn from the atmosphere during the growth period of crops. These $\mathrm{CO}_{2}$ emissions do, therefore, not contribute to the anthropogenic greenhouse effect. ${ }^{6}$ Fossil fuels required for biomass transport and processing as well as the production of auxiliaries (e.g., mineral fertilizers) are, however, accounted for. Furthermore, several LCA publications differentiate between terrestrial and aquatic eutrophication potential (e.g., Würdinger et al., 2002). Others chose a different methodology and give the eutrophication potential in totals only (e.g., Corbière-Nicollier et al., 2001; Müller-Sämann et al., 2002). We follow the latter approach and consistantly calculate eutrophication potential as sum of terrestrial and aquatic eutrophication, expressed in phosphate $\left(\mathrm{PO}_{4}\right)$ equivalents. Acidification potential is uniformly expressed in this analysis in sulphate $\left(\mathrm{SO}_{4}\right)$ equivalents. While analyzing bio-based energy, fuels and materials, and their fossil counterparts, land is only allocated to the production of bio-based products. This means that no reference land use was defined for fossil-based products because quantities required producing the latter are comparatively small (Weiss and Patel, in press).

We obtained the data for this analysis from the respective LCA publications. In a second step, we recalculated the environmental impacts consistently for one hectare (1 ha) of agricultural land. In the case of bio-based energy, fuels, and materials, this means that the results refer to the amount of energy, fuel or material that can be produced from the yield or a specific crop grown on one hectare of agricultural land (e.g., a yield of 38 tonnes of potatoes per hectare used to produce a certain amount of starch based loose-fill packaging material). For the petrochemical counterparts the equivalent amount of final product was chosen as a reference. ${ }^{7}$ Specific crop yields and data on biomass processing were taken from the respective LCA publications. In cases where agricultural yields are not reported, we used data from Katalyse (1998) as estimates. The relative environmental impact of bio-based and conventional product alternatives was calculated for each environmental impact category separately:

$$
\operatorname{REI}_{(i, k)}=\mathrm{EI}_{\text {bio-based }(i, k)}-\mathrm{EI}_{\text {fossil-based }(i, k)}
$$

\footnotetext{
${ }^{5}$ In this article, the term 'non-renewable energy consumption' refers to the consumption of non-renewable primary energy resources.

${ }^{6}$ The global warming potential of fossil-based greenhouse gas emissions is most likely calculated in the analyzed LCA studies on the basis of 100 years (see e.g., Corbière-Nicollier et al., 2001 or Würdinger et al., 2002). However, the LCA publications included in this analysis differ greatly with respect to the given background information. Therefore, we are not able to assess whether global warming potential is calculated consistently throughout all studies included in this analysis. The resulting differences from this possible methodological inconsistency are, however, minor with respect to the final results.

${ }^{7}$ Especially bio-based fuels and materials have slightly different properties (e.g., different heating values or densities) than their fossil counterparts. Equivalent amounts do, therefore, not necessarily mean similar mass or volume of products but equivalent use value or consumer satisfaction.
} 
with $\operatorname{REI}_{(i, k)}$ being the relative environmental impact equivalent of the bio-based versus fossil product alternative, expressed in gigajoule per hectare and year [GJ/(ha a)] or kilogram-equivalent per hectare and year $\left[\mathrm{kg}\right.$ equivalent/(ha a)], $\mathrm{EI}_{\text {bio-based }(i, k)}$ being the environmental impact equivalent of the bio-based product alternative and $\mathrm{EI}_{\text {fossil }(i, k)}$ the environmental impact equivalent of the fossil product alternative, with $i$ as index for the environmental impact category and $k$ as index for the product pair analyzed. As result of this approach, negative values indicate advantages of bio-based energy, fuels, and materials whereas positive values stand for environmental advantages of fossil product alternatives per hectare of agricultural land. ${ }^{8}$

\subsection{Weighing and aggregation of environmental impacts}

The distance-to target weighing methodology applied in this article consists of three steps, (i) normalizing the relative environmental impacts of bio-based and conventional products, (ii) weighing environmental impact categories, and (iii) aggregating the product specific values in each environmental impact category to one single environmental index. These three steps are explained below.

As distance-to-target we define the difference between the current level of an environmental pressure indicator and a future target value of the same indicator:

$$
\operatorname{DTT}_{(i)}=\mathrm{CEB}_{(i)}-\operatorname{FET}_{(i)}
$$

with $\mathrm{DTT}_{(i)}$ being the distance-to-target value in $[\mathrm{GJ} /(\mathrm{ha} a)]$ or $[\mathrm{kg} /($ ha a $)], \mathrm{CEB}_{(i)}$ the current environmental burden and $\mathrm{FET}_{(i)}$ the future environmental target for the environmental impact category $i$. We relate the current environmental burden and the future environmental target to the total agricultural land available in Germany. ${ }^{9}$ We chose this particular approach because bio-based products only have the potential to reduce environmental impacts to the extent that agricultural land is available for biomass production.

In the first step we normalize the relative environmental impacts of bio-based and conventional product alternatives by dividing them by the distance-to-target value:

$$
\operatorname{DN}_{\text {DTT }(i, k)}=\frac{\operatorname{EI}_{\text {bio-based }(i, k)}-\mathrm{EI}_{\text {fossil-based }(i, k)}}{\operatorname{DTT}_{(i)}}
$$

with DN $\mathrm{DTT}_{(i, k)}$ being the normalized relative environmental impact of a bio-based and fossil product alternative $k$ in the respective environmental impact category $i$. The goal of this normalization is two-fold: (i) to determine the specific contribution of a particular product alternative to reach a certain environmental target value and (ii) to obtain indices, which do not have a physical dimension. In this way, the normalized relative environmental impacts can be added to form one single environmental indicator. Based on the $\operatorname{DN}_{\mathrm{DTT}(i, k)}$ values, however, this would imply that all environmental impact categories and all environmental targets are per se equally important. In this analysis, however, we include additional specific

\footnotetext{
${ }^{8}$ The results obtained by this approach imply that we assume full substitution of fossil-based products by their bio-based counterparts.

${ }^{9}$ The available agricultural land in Germany is 17.041 million ha based on Destatis (2003).
} 
weighing factors for each environmental impact category. The problem with weighing is that it is always subjective and only scientifically justifiable to a limited extent. As criterion for the importance of a particular environmental impact category we chose the ratio of the current environmental burden to the future environmental target value. This way, an environmental impact category is ranked higher, the greater the ratio between the current environmental burden and a future target is:

$$
\mathrm{WF}_{(i)}=\frac{\mathrm{CEB}_{(i)}}{\mathrm{FET}_{(i)}}
$$

with $\mathrm{WF}_{(i)}$ being the weighing factor for an environmental impact category $i$. The combined environmental index value for each pair of bio-based and conventional energy, fuel, and material is then calculated by the following formula:

$$
\mathrm{CEI}_{(k)}=\sum_{i} \mathrm{WF}_{(i)} \times \mathrm{DN}_{\mathrm{DTT}(i, k)}
$$

with $\mathrm{CEI}_{(k)}$ being the cumulative environmental index of a particular product pair $k$ (consisting of a bio-based product and its conventional counterpart). The general methodology applied in this article is summarized in Fig. 1.

To define both the current environmental burden and future environmental targets, we refer to the situation in Germany (Table 1). The environmental targets in Germany represent benchmarks of sustainability, which were identified by scientific studies issued by the Fed-

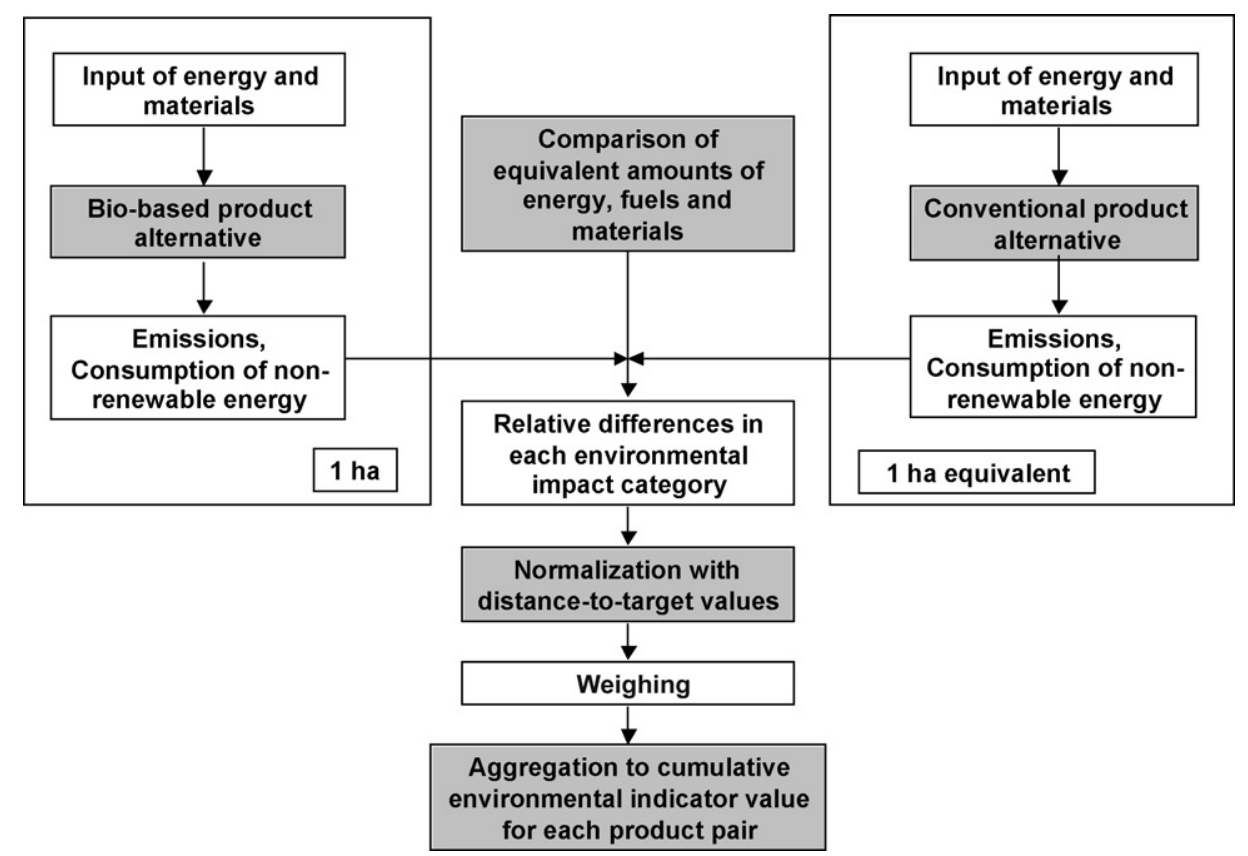

Fig. 1. Overview of the methodology applied to analyze the environmental performance of bio-based and conventional product pairs. 
Table 1

Current environmental burden and environmental target values for Germany

\begin{tabular}{|c|c|c|c|c|c|}
\hline Environmental impact category & $\begin{array}{l}\text { Current } \\
\text { environmental } \\
\text { pressure (year) }\end{array}$ & $\begin{array}{l}\text { Environmental } \\
\text { target }\end{array}$ & $\begin{array}{l}\text { Distance-to-target } \\
\text { value }\end{array}$ & $\begin{array}{l}\text { Weighing } \\
\text { factor }\end{array}$ & Source \\
\hline Non-renewable energy consumption (GJ/(ha a)) & $817(2000)$ & 251 & 566 & 3.2 & UBA $(2002 a, b)$ \\
\hline Global warming potential $\left(\mathrm{Mt} \mathrm{CO}_{2} /(\right.$ ha a $)$ & $48.8(2000)$ & 14.3 & 34.5 & 3.4 & BMU (2002), UBA (2002b) \\
\hline Eutrophication potential $\left(\mathrm{kg} \mathrm{PO}_{4} /(\text { ha a })\right)^{\mathrm{a}}$ & $78.4\left(1999 / 2000^{\mathrm{b}}\right)$ & 17.5 & 60.9 & 4.5 & UBA (2005) \\
\hline Acidification potential $\left(\mathrm{kg} \mathrm{SO}_{2} /(\mathrm{ha} \mathrm{a})\right)^{\mathrm{a}}$ & 442(1999) & 134 & 308 & 3.3 & UBA (2005) \\
\hline
\end{tabular}

a For terrestrial eutrophication and for acidification, the current environmental pressure and the future environmental target values base on critical load data (UBA,

2005). These data also refer to the area of one hectare. However, the values in Table 1 are recalculated for one hectare of agricultural land, on which potential reduction of environmental impacts of products can be realized. The data in Table 1 are therefore not identical with the critical loads of ecosystems as stated by UBA (2005). For a more detailed description of the recalculation method chosen, the reader is referred to Weiss (2004).

b Data for aquatic eutrophication are available for 2000 whereas data for terrestrial eutrophication are only available for the year 1999 (UBA, 2005). 
eral Environmental Agency of Germany and can therefore be used for the assessment of environmental priorities and their integration into product and production related decisions. ${ }^{10}$

A sensitivity analysis is conducted to identify the impact of different weighing factors on the final result of our analysis (Table 2). The chosen scenarios for the sensitivity analysis are based on the qualitative evaluation of impact categories by UBA (1999) (Sensitivity-I) and the assumption that all categories are equally important (Sensitivity-II). In the other two scenarios we take a global perspective (global warming potential most important impact, Sensitivity-III) and a regional perspective with eutrophication and acidification being most important (Sensitivity-IV). Weighing factors for the sensitivity scenarios III and IV are chosen to reflect extreme cases. They therefore reflect explorative choices made by the authors and are not based on scientific evidence.

For final characterization, we divide the various options for biomass use into three categories, i.e. energy (power and heat), fuels, and materials. Median values ${ }^{11}$ of the cumulative environmental indices are calculated separately for each of the three utilization options and tested for statistical differences with the Mann-Whitney $U$-test. ${ }^{12}$

\section{Results}

In this section, we first present the results for the normalized relative environmental impacts of bio-based products and their conventional counterparts in each of the four impact categories. Afterwards, we give the cumulative environmental indices for each product pair and we show results of the comparative analysis for the three options for biomass utilization.

\subsection{Normalized environmental impacts}

The normalized relative differences between bio-based and conventional products show large variations, both between single product alternatives and among the different environmental impact categories (Fig. 2). ${ }^{13}$

\footnotetext{
${ }^{10}$ Defining the current environmental burden, we refer to the years 1999 and 2000 in order to assure consistency because the most recent data for eutrophication and acidification in Germany are only available for these years (UBA, 2005).

11 We chose the median here and not the arithmetic mean because the former is more resistant against statistical outliers. This is of special importance for this analysis because the sample sizes are small and do not conform to a Gaussian distribution.

12 The Mann-Whitney $U$-test is a non-parametric test suitable to compare test samples, which are typically small and which do not show Gaussian distribution (Kottegoda and Rosso, 1997).

13 The normalized relative environmental impacts as presented in Fig. 2 have no physical unit and represent the specific contribution of a product pair for reaching the future environmental target in one particular environmental impact category. A value of -1 , for example, indicates that the environmental target could be reached, if biomass used to manufacture a particular bio-based product were grown on the total agricultural land available in Germany (i.e., 17 million ha). By analogy, -2 means that using $50 \%$ of the total farmland for a particular biomass option would be sufficient for reaching the environmental target, while -0.5 indicates that twice as much farmland as available would be required tom future environmental targets. A positive value of 1 , on the other hand, indicates that the target value could be reached, if the quantity of bio-based products manufactured from the biomass, grown on all German agricultural land, would be substituted by a conventional, fossil-based product equivalent.
} 
Table 2

Weighing factors applied in the sensitivity analysis

\begin{tabular}{|c|c|c|c|c|c|}
\hline Environmental impact category & $\begin{array}{l}\text { Standard } \\
\text { scenario }^{\mathrm{a}}\end{array}$ & $\begin{array}{l}\text { Sensitivity-scenario } \\
\mathrm{I}^{\mathrm{a}}\end{array}$ & $\begin{array}{l}\text { Sensitivity-scenario } \\
\mathrm{II}^{\mathrm{a}}\end{array}$ & $\begin{array}{l}\text { Sensitivity-scenario } \\
\text { III }^{\mathrm{a}}\end{array}$ & $\begin{array}{l}\text { Sensitivity-scenario } \\
\text { IV }^{\mathrm{a}}\end{array}$ \\
\hline Non-renewable energy consumption (GJ/(ha a)) & 3.2 & 1.8 & 3.6 & 4.8 & 0.8 \\
\hline Global warming potential $\left(\mathrm{Mt} \mathrm{CO}_{2} /(\mathrm{ha} a)\right)$ & 3.4 & 5.4 & 3.6 & 7.2 & 1.5 \\
\hline Eutrophication potential $\left(\mathrm{kg} \mathrm{PO}_{4} /(\mathrm{ha} a)\right)$ & 4.5 & 3.6 & 3.6 & 1.2 & 7.5 \\
\hline Acidification potential $\left(\mathrm{kg} \mathrm{SO}_{2} /(\right.$ ha a $\left.)\right)$ & 3.3 & 3.6 & 3.6 & 1.2 & 4.6 \\
\hline
\end{tabular}

Acidification potential $\left(\mathrm{kg} \mathrm{SO}_{2} /\right.$ (ha a) $)$

1.2

a The totals of all weighing factors have to be equal in order to assure compatibility of the results obtained for the different sensitivity scenarios. 


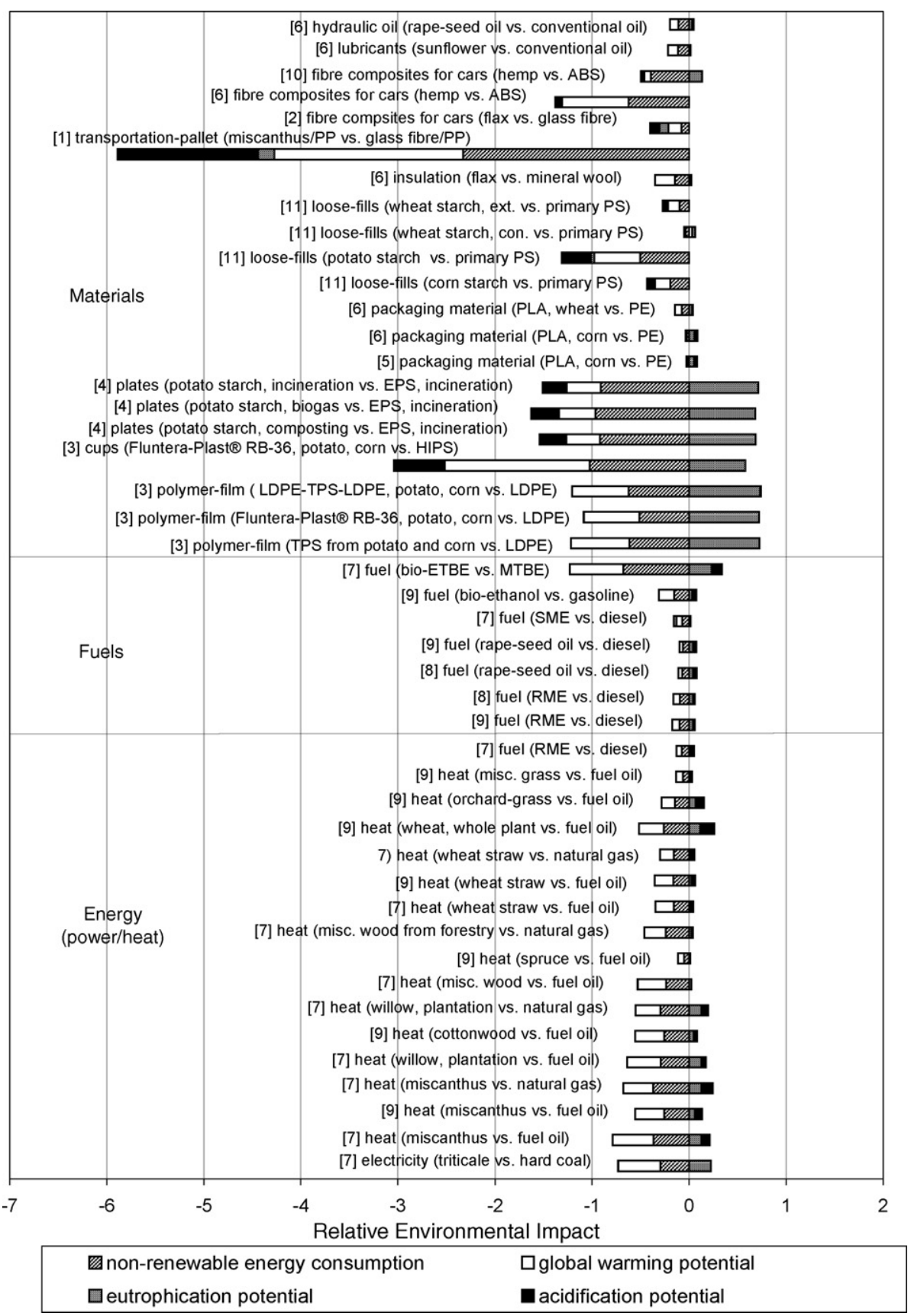

Fig. 2. Normalized relative environmental impacts of bio-based and conventional product alternatives ([1] Corbière-Nicollier et al., 2001; [2] Diener and Siehler, 1999; [3] Dinkel et al., 1996; [4] Dinkel and Waldeck, 1999; [5] Gärtner et al., 2002; [6] Müller-Sämann et al., 2002; [7] Reinhardt et al., 2000; [8] Reinhardt and Gärtner, 2003; [9] Reinhardt and Zemanek, 2000; [10] Wötzel et al., 1999; [11] Würdinger et al., 2002). 


\subsubsection{Non-renewable energy consumption}

All bio-based product alternatives consume less non-renewable energy resources than their fossil counterparts during their entire life cycle. The values range from around -2.33 for the miscanthus-fibre/polypropylene $(\mathrm{PP})^{14}$ transport pallet to -0.01 for polylactic acid (PLA) packaging material produced from cornstarch. The outstandingly high value of the miscanthus-fibre/PP transport pallet can possibly be explained by (i) the relatively high hectare specific yield of miscanthus, (ii) the large proportion of the crop (70\%) that is usable for fibre-composite production but also by (iii) the high resource and energy requirements for the production of the conventional glass fibre/PP pallet.

Substantial savings of non-renewable energy can also be achieved with disposable plates, cups and polymer films made from potato and potato/corn starch $(-0.51$ to -1.02$)$. Ethyl-tertiary-butyl-ether (ETBE) produced from sugar beet and used as a substitute for the anti-knock additive methyl-tertiary-butyl-ether (MTBE) scores best among all fuels included in this analysis $(-0.68)$. The substitution of conventional packaging materials by corn or wheat based bio-materials and also the replacement of conventional diesel by rape-seed methyl-ester (RME), sunflower methyl-ester (SME) or rape-seed oil offers comparatively minor savings of non-renewable energy ( -0.06 to -0.10$)$. Regarding RME and SME, principally the energy intensive chemical conversions from raw oil to final fuel products prevent better performance of the bio-based product alternatives compared to their conventional counterparts. The relatively poor performance of packaging materials produced from corn or wheat $(-0.01$ to -0.08$)$ is caused by the relatively low specific yields of crops used as starch source.

\subsubsection{Global warming potential}

The results for this category vary from -1.95 for the miscanthus/PP transport pallet to +0.03 for loose-fill packaging material made from wheat starch. The results are strongly correlated with the outcome in the category of non-renewable energy consumption because energy production is the main source of fossil $\mathrm{CO}_{2}$ emissions. Consequently, products that consume the least non-renewable energy sources throughout their entire life cycles offer also the greatest reduction potential of $\mathrm{CO}_{2}$ emissions.

\subsubsection{Eutrophication potential}

The total results in this category range between -0.16 for the transport pallet and around +0.73 for polymer films made from corn and potato starch. In general, bio-based energy, fuels, and materials increase the environmental burden compared to their fossil counterparts. Exceptions are, among others, the miscanthus/PP transport pallet and the fibre-reinforced composite for cars $(-0.09)$. The poor performance of bio-based products in this category is largely caused by biomass production using conventional farming practices. Here, nitrate leaching and particulate transport of phosphate to surface and ground waters from fertilizer application as well as ammonia emissions from manure can be identified as the main sources of eutrophication. However, improved soil cultivation practices, e.g. extensive and low- or non-tillage farming, can reduce fertilizer losses substantially by (i) reducing the total amount

\footnotetext{
${ }^{14}$ For this product alternative, only the fibres are produced from biomass, i.e., miscanthus. The polypropylene (PP) part is made from conventional fossil feedstock.
} 
of fertilizers applied, (ii) improving the seasonal management of fertilizer application, and (iii) reducing overall soil erosion from agricultural farmland. Precision farming may also contribute to reduce the share of fertilizer losses, e.g., by leaching.

\subsubsection{Acidification potential}

The results in this category range from -1.45 for the miscanthus/PP transport pallet to +0.15 for heat produced from wheat versus fuel oil. Relative to their fossil counterparts, disposable plates and cups made from potato/corn starch as well as loose-fill packaging materials produced from potato starch have the potential to reduce acidification considerably. By contrast, the generation of heat from wheat or china reed and the production of RME and especially ETBE produced from sugar beet $(+0.11)$ increase acidification compared to their fossil product alternatives. In general, the use of biomass for manufacturing materials (polymers and fibre composite products) can help to reduce acidification. By contrast, acidification is increased, if biomass is used to replace fossil resources used for the production of energy (power/heat) and transportation fuels. The specific acidification potential for energy, fuels, and materials is largely caused by sulphur and nitrogen oxide emissions resulting from incineration processes. This holds for both bio-based and conventional products. In addition, ammonia emissions from manure application are typically a source for acidification caused by bio-based products.

\subsection{Cumulative environmental indices}

In the next step of our analysis, we weigh the normalized environmental impacts and aggregate the results to one cumulative environmental index (Fig. 3). The values range from -19.72 for the miscanthus/PP palette to +0.25 for packaging materials produced from cornstarch. Apart from three options of starch-based packaging materials manufactured from corn and wheat, all products show negative values, hence indicating the potential of bio-based products to reduce environmental impacts compared to their conventional counterparts. Relatively low environmental impacts are related to single-use cups ( -7.57$)$, hemp fibre reinforced car composites (-4.49), and bio-ethanol (-2.69).

The median values for energy $(-1.16)$ and materials $(-1.02)$ are clearly below the one for fuels $(-0.32)$. The environmental index for materials shows the highest variation among the three options for biomass use (Fig. 4). The results of the Mann-Whitney $U$-test indicate, that differences between energy and materials on the one hand and fuels on the other are significant, while the differences between energy and materials are not significant (at a significance level of $\alpha=0.05$ ).

Both medians and individual values vary depending on the applied weighing factors for each impact category (see also Table 2). The two extreme scenarios in the sensitivity analysis are scenarios III and IV. Given the current environmental discussion with a focus on climate change and the depletion of non-renewable energy resources, impact weighing as it is done in the sensitivity Scenario-III reflects the priorities on mitigation of global environmental impacts especially through anthropogenic greenhouse gas emissions. For that purpose, global warming potential is weighted six times higher than eutrophication and acidification. The sensitivity scenario IV takes a local/regional perspective while assuming eutrophication and acidification to be more relevant than, e.g., global warming potential 


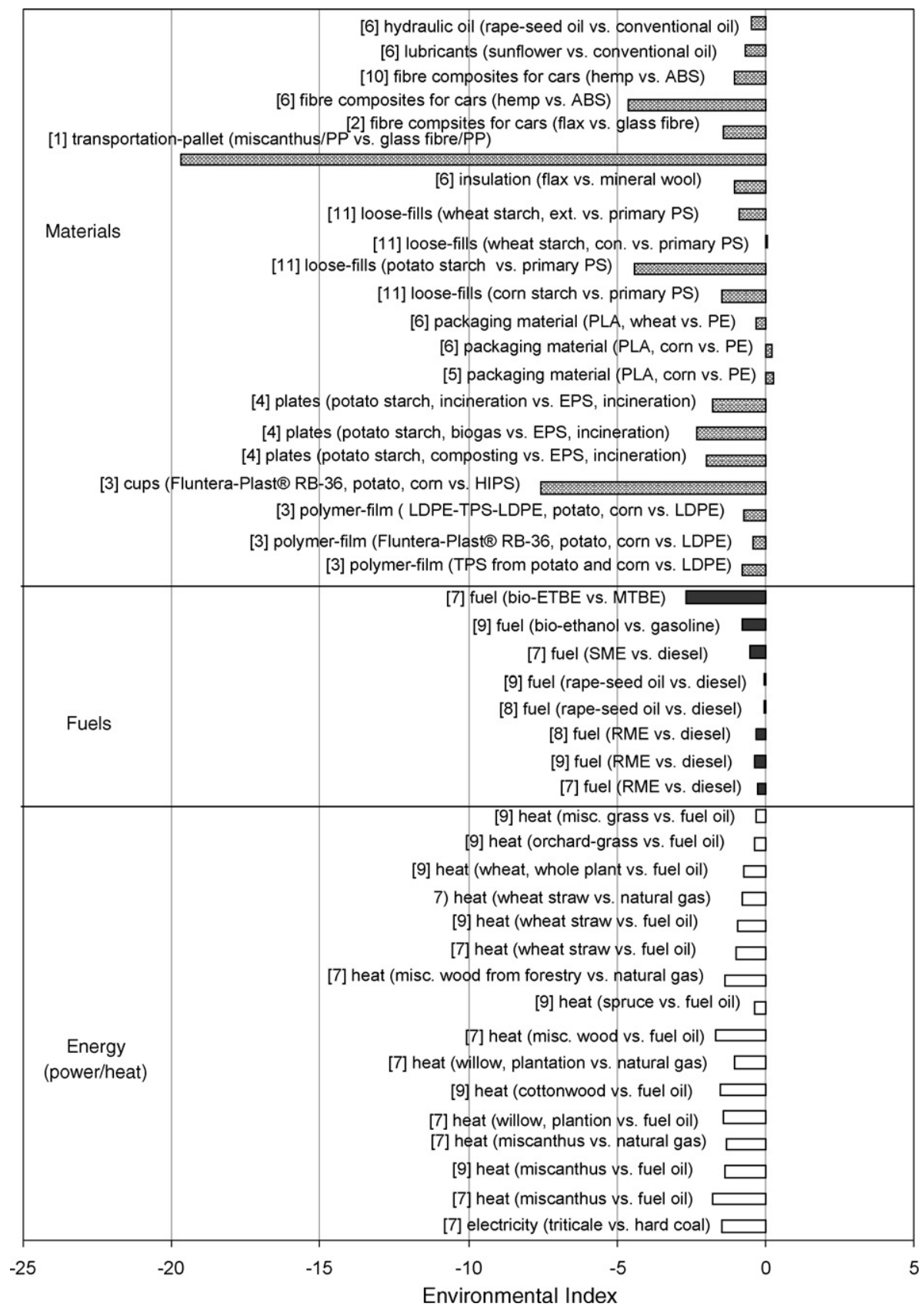

Fig. 3. Cumulative environmental index for bio-based energy, fuels, materials, and their conventional counterparts (for references see caption of Fig. 2). 


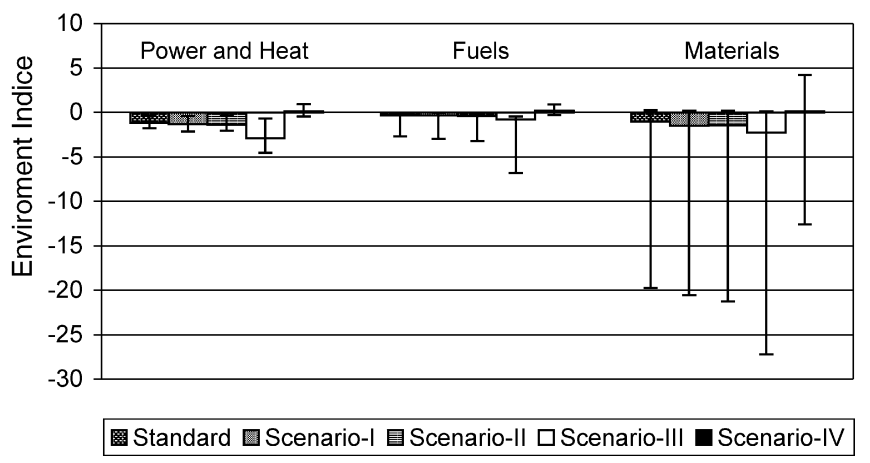

Fig. 4. Results and sensitivity of medians and value ranges for the cumulative environmental indices.

(see also Table 2). ${ }^{15}$ In all sensitivity scenarios, bio-fuels score on average worse than bio-energy and bio-materials. While bio-based products are favourable compared to their conventional counterparts in the sensitivity scenarios I-III, this is not the case for scenario IV where fossil-based energy, fuels, and materials score better than their bio-based product equivalents. This is because eutrophication, an impact category where bio-based products are generally inferior to fossil-based ones, is attributed with the highest weighing factor. The results of the sensitivity analysis demonstrate that weighing of impact categories has a profound impact on the final outcome of the analysis (see also Section 4.2).

\section{Discussion}

In the first part of the discussion, we focus on methodological aspects and uncertainties related to our analysis. In the second part, we discuss the main results and their implication for future research as well as for decisions regarding the promotion of bio-based products in greater detail.

\subsection{Discussion of distance-to-target weighing methodology}

The results presented in this article are based on the most important comparative LCA studies on bio-based energy, fuels, and materials published. The studies analyzed, however, vary considerably regarding system boundaries, allocation methods, waste management, and the treatment of agricultural residues. Uncertainties related to both methodological choices as well as errors resulting from data collection may have a significant effect on the outcome of individual life cycle assessment studies. For a more detailed discussion of the effect of these parameters on the primary results of our analysis, i.e., direct environmental

15 An example could be the Erzgebirge region in southern Saxony, Germany where (i) dramatic damage of spruce forests occurred in the 1980s due to deposition of acidifying substances emitted by large scale lignite and briquette combustion (Bitter et al., 1998) and (ii) eutrophication of surface waters continues to be a problem due to run-off from agricultural land along side mountain slopes. 
impacts of product alternatives in the respective impact categories, we refer to Weiss et al. (2004) and Weiss and Patel (in press).

The normalized results obtained for each product pair in the respective environmental impact category strongly depend on the level of both the current environmental burden and the future environmental target. The reference year chosen for the current level of environmental burden is critical for the results of the normalization, especially for the categories of eutrophication and acidification, where environmental impacts were reduced substantially in the last years. It is therefore likely that the values from 1999/2000 used in our analysis overestimate current levels of eutrophication and acidification in Germany to a larger extent than they overestimate greenhouse gas emissions and consumption of non-renewable energy resources. These findings might also have a significant impact on the weighing factors applied for the respective environmental impact categories. While the weighing factors chosen for this analysis range between 4.5 for eutrophication and 3.2 for the consumption of non-renewable energy resources (see Table 2), a substantial decrease of eutrophying and acidifying emissions might have resulted in much lower weighing factors for these impact categories. This is considered in the sensitivity analysis (scenario III), where a lower weight assigned to the categories of eutrophication and acidification leads to lower average values of the environmental index (see Fig. 4) and hence to a better overall performance of biobased products compared to their fossil counterparts. An increased production of biomass for non-food purposes may, however, also lead to large-scale, intensive biomass cultivation and reduced attention to avoid higher residuals of contaminants in the harvested biomass, soil and groundwater. This could lead to increased eutrophication and local environmental pressure, which is reflected in the scenario IV. In this weighing scenario, bio-based substitutes on the average are no longer preferable to fossil based products.

Furthermore, normalization with distance-to-target values may lead to biased results because small distances between current environmental pressures to future targets lead to relatively high normalized values for the respective environmental category. Conversely, large distance-to-target values, cause relatively small normalized differences as it is shown below:

$$
\begin{aligned}
& \lim _{\left(\mathrm{CEB}_{(i)}-\mathrm{FET}_{(i)}\right) \rightarrow 0}\left(\frac{\mathrm{EI}_{\text {bio-based }(i)}-\mathrm{EI}_{\text {fossil-based }(i)}}{\mathrm{CEB}_{(i)}-\mathrm{FET}_{(i)}}\right)=\infty \\
& \lim _{\left(\mathrm{CEB}_{(i)}-\mathrm{FET}_{(i)}\right) \rightarrow \infty}\left(\frac{\mathrm{EI}_{\text {bio-based }(i)}-\mathrm{EI}_{\text {fossil-based }(i)}}{\mathrm{CEB}_{(i)}-\mathrm{FET}_{(i)}}\right)=0
\end{aligned}
$$

This feature is problematic because the values resulting from normalization will be highest for environmental categories where the distance-to-target is smallest, i.e., where the environmental target value is almost reached. To partly compensate for this effect, we introduced weighing factors for each environmental impact category as follows:

$$
\begin{aligned}
\lim _{\left(\mathrm{CEB}_{(i)}-\mathrm{FET}_{(i)}\right) \rightarrow 0}\left(\frac{\mathrm{CEB}_{(i)} \times\left(\mathrm{EI}_{\text {bio-based }(i)}-\mathrm{EI}_{\text {fossil-based }(i)}\right)}{\mathrm{FET}_{(i)} \times\left(\mathrm{CEB}_{(i)}-\mathrm{FET}_{(i)}\right)}\right) & =\infty \\
\lim _{\left(\mathrm{CEB}_{(i)}-\mathrm{FET}_{(i)}\right) \rightarrow \infty}\left(\frac{\mathrm{CEB}_{(i)} \times\left(\mathrm{EI}_{\text {bio-based }(i)}-\mathrm{EI}_{\text {fossil-based }(i)}\right)}{\mathrm{FET}_{(i)} \times\left(\mathrm{CEB}_{(i)}-\mathrm{FET}_{(i)}\right)}\right) & =0
\end{aligned}
$$


However, the general mathematical characteristics of the cumulative environmental index are identical to those of the normalized difference values.

While the current environmental pressures studied are measurable environmental parameters, this is not the case for the future target values. The latter are only to a certain extent scientifically based because they also reflect subjective value judgements and express political priorities. The environmental targets used for this analysis are only valid for Germany. This implies that other countries may define different environmental targets than the ones chosen here. The regional scope of distance-to-target weighing methodology is also important because large parts of the environmental impacts of agricultural biomass production have a local or regional impact (e.g., surface and ground water eutrophication). Substantial changes in either the environmental targets or the distance-to-target values between countries or regions will certainly affect the environmental indices calculated in this article. As the sensitivity analysis demonstrates, different priorities on a regional scale can lead to different weighing factors for each environmental category and might ultimately lead to different conclusions regarding the superiority of one product alternative over another. The cumulative environmental index reflects all of these characteristics.

Finnveden et al. (2002) developed a set of criteria for the evaluation of weighing methods. One main argument stated against distance-to-target methodology is that this method usually assumes equal importance of different environmental impact categories. We account for this argument and weigh the different impact categories with a quotient of the current environmental pressure and its future environmental target.

Furthermore, and this seems to be the most important reservation for the interpretation of the results, the environmental categories considered in this analysis reflect only a part of the potential environmental impacts caused by bio-based and conventional products. Other important effects such as eco- and human-toxicity, stratospheric ozone depletion, degradation of biodiversity, and implications on global land use are not addressed in this analysis. This is not only due to the weak data situation in the individual LCA publications, it also reflects that there is still a considerable lack in the provision of harmonized LCA impact categories. Moreover, some impact categories such as eco-toxicity, biodiversity and land use seem to be hardly accessible with the LCA methodology and call for a widening of the analytical framework.

The results presented in this article, therefore, highly depend on the selection of impact categories, which seem to be somewhat biased towards issues related to fossil energy consumption (which cause also acidification) and they are also influenced by the specific distance-to-target methodology chosen. A different weighing methodology would have most likely resulted in different outcomes than the ones presented here. For example, Daniel et al. (2004) studied the effect of various environmental impact assessment methods on LCA results for two alternative end-of-life scenarios of used starter batteries. Using the same life cycle inventory data, they found tremendous differences in the results depending on the assessment method chosen. This finding reflects the dilemma of weighing in general because it shows the variability of the final result depending on factors, values, and standards chosen for final evaluation.

As a consequence, the result of a weighing procedure must always be seen in close conjunction with the basic assumptions and meaning of the valuation procedure. In this 
analysis, the comparative assessment of substitutive effects of bio-based energy, fuels, and materials are evaluated on the basis of only four impact categories for which environmental targets exist. If these are taken as indicators of political priorities, the outcomes do provide some orientation.

\subsection{Discussion of the results}

The results show the environmental potential of biomass replacing conventional fossil resources for the production of energy, fuels, and materials. The cumulative environmental index for the various product pairs shows relatively small variation for energy and fuels but large value ranges for materials. The median values calculated for the different options of biomass utilization, i.e., energy $(-1.16)$, fuels $(-0.32)$, and materials $(-1.02)$ show that bio-energy and bio-materials offer greater potentials to reduce negative environmental impacts than bio-fuels. ${ }^{16}$ These results are largely caused by the relative energy intensive conversion of plant oils into final fuel products. The direct consumption of rape-seed or sunflower oils for transportation and the increased utilization of bio-ethanol would certainly reduce negative environmental impacts associated with bio-fuels.

Compared to all other product alternatives studied, the result for the transport pallet (miscanthus/PP versus glass-fibre/PP) is exceptional. The extreme index of -19.7 demonstrates the importance of the chosen fossil product equivalent on the final results of a comparative LCA. A less energy and material intensive product alternative than glass-fibre/PP (e.g., conventional PP pallets or even wood pallets) would have, most certainly, reduced the environmental benefits of the miscanthus/PP pallet compared to the fossil counterpart. In a positive sense one may conclude that the substitution of bio-based products for fossil ones make more sense the higher the energy intensity of conventional products is.

For the interpretation of the final environmental index values it is important to note that energy and fuels can be produced from biomass by using largely conventional technologies (e.g., co-firing of biomass in conventional coal/lignite fired power plants, transesterification of rape-seed oil to rape-seed methyl-ester). This is only to a much lesser extent the case for materials produced from biomass. As a consequence, bio-materials are still in their infancy and LCA data are often based on small plants operating in the pilot phase. Hence, further reductions of negative environmental impacts of bio-materials can be expected from technological improvements and scale effects of mass production of bio-materials in the future.

Regarding the reduction potential of negative environmental impacts it is, furthermore, important to note that bio-materials (especially the ones included in this analysis) are niche products compared to bio-energy and bio-fuels. Even the market volumes of conventional loose-fill packaging materials, polymer-films or car panels are small compared to the markets for energy and fuels. While the potential to reduce the environmental impacts is relatively high for materials on the level of individual products, the overall societal reduction potential of environmental impacts depends on the future total demand for bio-materials

\footnotetext{
${ }^{16}$ However, the results in Fig. 3 indicate the relatively high environmental potential of bio-ethanol compared to RME produced from rape-seed. The conclusion stated here might change, if this analysis had included more LCA studies on bio-ethanol.
} 
and still needs to be explored. The current development is characterized by a subsidization of energy and fuel production from biomass. The technologies for bio-fuel production may be used as an interim step towards the implementation of bio-refineries, which in the long run may primarily produce bio-materials (with the energy content being recovered after the end of the life cycle of the resulting products).

The most important limitation to the wide application of biomass in the medium and long term arises from the availability of agricultural land. Most of the agricultural land is currently used for the production of food and feed. Set-aside land in the EU represents only a small proportion (below 10\% of total agricultural land) and is already used for the production of non-food biomass (Bringezu and Steger, 2005). The global agricultural land use of the EU exceeds the domestic agricultural land by nearly 20\% (Bringezu and Steger, 2005). The situation in the new member states is not significantly different from the EU15 in terms of land availability for non-food purposes (Kavalov et al., 2003). Significant potentials for biomass production exist in the tropics, however, the expansion of arable land for products such as sugar cane or soy beans often comes at the expense of natural forests and grasslands. A rising demand of bio-fuels or bio-materials in the EU will probably contribute to the expansion of global arable land and the degradation of natural ecosystems (Bringezu and Steger, 2005). In addition, long distance transportation of raw biomass, intermediate and final products from continents such as South America to consumers in Europe would partly reduce the energy and emission reduction benefits of bio-based products.

The results of the different weighing scenarios underline a fundamental trade-off between local and regional environmental impacts on the one hand and global impacts on the other. If local and regional targets for environmental improvement were to be given highest priority (as in scenario IV), then bio-based products should not be preferred against fossil based conventional products. ${ }^{17}$ However, the existing policy targets strike a certain balance in reaching environmental quality targets for local and regional as well as global environmental relief (which is reflected by similar weighing factors, see Table 2). Nevertheless, the use of biomass for mitigating global environmental problems can to date only be realized if significant local and environmental effects are accepted such as land use for biomass production and the associated environmental pressure.

The ecological disadvantages of bio-based products in the impact categories of eutrophication and acidification mainly arise from biomass production with conventional agricultural practices. Würdinger et al. (2002) have shown in their LCA study on loose-fills produced from wheat starch that extensive farming practices offer great potential for reducing environmental impacts compared to conventional farming practices in all four environmental categories. These results demonstrate that bio-based products do not score per se worse than conventional products with respect to eutrophication. Future biomass production should, therefore, aim (i) to reduce losses of fertilizer, manure and pesticides to the environment by improved management and application and (ii) to reduce on site soil erosion by, for example, non- or low-tillage cultivation practices. A reduction of eutrophication potential associated with biomass production remains, however, doubtful, if farming practices will

\footnotetext{
17 This statement holds considering the four environmental impact categories analyzed in this article. The inclusion of other categories might, however, change this conclusion.
} 
not be changed. At the same time, additional environmental impacts may arise from the use of genetically modified crop varieties. These impacts, especially on human health and biodiversity, are to date subject to ongoing research activities (e.g., Rischer and OksmanCaldertey, 2006; Thompson et al., 2003; Myhr, 2002).

While considerable attention is paid in LCA studies and ongoing research to issues related to agricultural production and waste management, relatively little is known about the total environmental impact and improvement potentials for the conversion of bio-based feedstock to new fuels, materials and chemicals. This holds, in particular, for biotechnological processes as, for example, applied for the production of PLA and ethanol (note that all other products shown in Figs. 2 and 3 imply conventional chemical conversion, simple blending or incineration). In view of substantial progress being made in biotechnology, major opportunities for reducing environmental impacts are expected. To exploit them fully, technological as well as logistical shortcomings need to be overcome (Weiss and Patel, in press).

\section{Conclusions}

The ecological evaluation of bio-based products is complicated by the fact that these products have both positive and negative environmental effects compared to their fossil counterparts. Weighing of different environmental impacts, therefore, always requires decisions regarding the priorities of impact assessment in order to evaluate the overall environmental performance of a particular product. The information available for this decision finding consists in most cases of a mixture of scientific knowledge, assumptions and subjective value judgements. In the current environmental debate, the focus is clearly on savings of non-renewable energy resources and greenhouse gas emissions. However, this one-sided emphasis is often driven by a global perspective and disregards environmental impacts relevant on a regional level such as eutrophication or acidification. In this article, we introduce distance-to-target methodology as an attempt to comparatively evaluate the environmental performance of bio-based energy, fuels, and materials. The results of this analysis demonstrate that the potential of bio-based products to reduce negative environmental impacts compared to their fossil counterparts strongly depends on the value assumptions.

Given the uncertainties and the subjectivity associated with the applied methodology, we do, however, not recommend applying distance-to-target weighing as an inherent step of LCA. Rather, we emphasize that weighing can be used as an additional step at the level of practitioners and stakeholders aiming for decisions based on LCA results. As such, this article goes beyond conventional LCA methodology and demonstrates a certain rationale (in a real case example for bio-based products and their conventional counterparts) for decision support in business, society and policy. The discussion of the results of the applied distanceto-target methodology reflects the related uncertainties and problems associated with the approach chosen. Despite the methodological shortcomings discussed above, we conclude that this analysis gives not only valuable insights into the environmental performance of bio-based energy, fuels, and materials but also into the boundaries and potentials of distanceto-target weighing methodology. 


\section{References}

APME-Association of Plastics Manufacturers Europe. Eco-profiles of polymers and related intermediates (about 55 products). Brussels, Belgium; 1999 [source: http://www.apme.org; 4 April 2005].

Bitter AW, Eilermann F, Gerold D, Küßner R, Röhle H, Wienhaus O, et al. Waldentwicklung und Schadgeschehen. In: Nebe W, Roloff A, Vogel M, editors. Untersuchung von Waldökosystemen im Erzgebirge als Grundlage für einen ökologisch begründeten Waldumbau. Forstwissenschaftliche Beiträge Tharandt, 4; 1998. p. 50-7.

BMU—Bundesministerium für Umwelt, Naturschutz und Reaktorsicherheit. Umweltbericht 2002—Bericht über die Umweltpolitik der 14. Legislaturperiode. Referat Öffentlichkeitsarbeit am BMU. Berlin, Germany; 2002.

Bringezu S, Steger S. Bio-fuels and competition for global land use. In: Berger H, Prieß R, editors. Bio im Tank. Chancen-Risiken-Nebenwirkungen. Conference documentation of conference series "Kyoto + Lab" of the Heinrich-Böll-Foundation and the European Climate Forum. Global Issue Papers No. 20; 2005. p. 64-79 [source: http://www.boell.de/de/04_thema/3612.html; 10 December 2005].

CEN_Comité Européen de Normalisation. EN ISO 14042 Umweltmanagement-Ökobilanz: Wirkungsabschätzung. DIN—Deutsches Institut für Normung. Beuth Verlag GmbH Berlin, Germany; 2000.

Corbière-Nicollier T, Gfeller-Laban B, Lundquist L, Leterrier Y, Månson J-AE, Jolliet O. Life cycle assessment of bio fibres replacing glass fibres as reinforcement in plastics. Resour Conserv Recycl 2001;33:267-87.

Daniel SE, Tsoulfas GT, Pappis CP, Rachaniotis NP. Aggregating and evaluating the results of different environmental impact assessment methods. Ecol Indicators 2004;4:125-38.

Destatis-Statistisches Bundesamt. Statistische daten online; 2003 [source: www.destatis.de/basis/d/umw/ ugrtab8.htm; 09.01.2004].

Diener J, Siehler U. Ökologischer Vergleich von NMT-und GMT-Bauteilen. Die Angewandte Makromolekulare Chemie 272. Seiten; 1999. p. 1-4.

Dinkel F, Pohl C, Ros M, Waldeck B. Ökobilanz stärkehaltiger Kunststoffe. Carbotech AG for: Bundesamt für Umwelt, Wald und Landschaft (BUWAL), Bundesamt für Landwirtschaft (BLW) and Fluntera AG. Schriftenreihe Umwelt NR. 271/I-II. Bern, Switzerland; 1996.

Dinkel F, Waldeck B. Ökologische Beurteilung verschiedener Geschirrtypen mit Empfehlungen. Arbeitspapier 4/99. Carbotech AG; 1999 [source: www.kompost.ch; 27.10.2003].

Dornburg V, Lewandowski I, Patel M. Comparing the land requirements, energy savings, and greenhouse gas emissions reduction of bio-based polymers and bio-energy. J Ind Ecol 2004;7(3-4):93-116.

Finnveden G, Hofstetter P, Bare JC, Basson L, Ciroth A, Mettier T, et al. Normalization, grouping, and weighing in life-cycle impact assessment. In: de Haes U, et al., editors. Life-cycle impact assessment: striving towards best practice. Penascola FL, USA: Society of Environmental Toxicology and Chemistry (SETAC); 2002. p. 177-205.

Gärtner SO, Müller-Sämann K, Reinhardt GA, Vetter R. Corn to plastics: a comprehensive environmental assessment. In: Pala W, et al., editors. Proceedings of the 12th European conference on biomass for energy, industry and climate protection, vol. II; 17-22 June 2002. p. 1324-6 [ETH-Florence].

Kaenzig J, Houillon G, Rocher M, Bewa H, Bodineau L, Orphelin M, et al. Comparison of the environmental impacts of bio-based products. In: Proceedings of the 2nd world conference and technology exhibition on biomass for energy, industry and climate protection; 10-14 May 2004.

Katalyse-Institut für angewandte Umweltforschung. Leitfaden Nachwachsende Rohstoffe. 1. Auflage. 270 Seiten. Heidelberg: C.F. Müller Verlag; 1998, ISBN 3-7880-75961.

Kavalov B, Jensen P, Papageorgiou D, Schwensen C, Olsson JP. Bio-fuel production potential of EU-candidate countries. JRC-IPTS, ESTO, Report EUR 20835. Sevilla, Spain; 2003.

Kottegoda NT, Rosso R. Statistics, probability, and reliability for civil and environmental engineers. USA: Mc Graw-Hill Companies, Inc; 1997.

Müller-Sämann KM, Reinhardt G, Vetter R, Gärtner S. Nachwachsende Rohstoffe in Baden-Württemberg: Identifizierung vorteilhafter Produktlinien zur stofflichen Nutzung unter Berücksichtigung umweltgerechter Anbauverfahren. Forschungsbericht FZKA-BWPLUS; 2002 [source: http://www.inaro.de; 12.08.2003].

Myhr AI. Precaution, context and sustainability. A study of how ethical values may be involved in risk governanace of GMOs (genetically modified organisms). Ph.D. thesis. Troms $\varnothing$, Norway: Department of Microbiology and Virology, Institute of Medical Biology; 2002. 
Patel M, Bastioli C, Marini L, Würdinger E. Life cycle assessment of bio-based polymers and natural fibers. Biopolymers, vol. 10. Wiley-VCH; 2003. p. 409-52.

Reinhardt GA, Calzoni J, Caspersen N, Dercas N, Gaillard G, Gosse G, et al. Bio-energy for Europe: which one fits best? A comparative analysis for the community. Final Report; 2000 [source: http://www.ifeu.de; 25.07.2003].

Reinhardt GA, Gärtner SO. Biodiesel or pure rape-seed oil for transportation: which one is best for the environment? Study of IFEU-Institut für Energie-und Umweltforschung Heidelberg GmbH. In: Bartz WJ, editor, Proceedings of the 4th international colloquium "Fuels 2003", Ostfildern(D). Technische Akademie Esslingen, Germany; 15-16 January 2003. p. 111-14.

Reinhardt GA, Zemanek G. Ökobilanz Bioenergieträger: Basisdaten, Ergebnisse, Bewertungen. Berlin, Germany: Erich Schmidt Verlag; 2000, ISBN 3-503-05814-1.

Rischer H, Oksman-Caldertey KM. Unintended effects in genetically modified crops: revealed by metabolomics? Trends Biotechnol 2006;24(3):102-4.

Thompson CJ, Thompson BJP, Ades PK, Cousens R, Garnier-Gere P, Landman K, et al. Model-based analysis of the likelihood of gene introgression from genetically modified crops into wild relatives. Ecol Model 2003;162(3):199-209.

UBA-Umweltbundesamt. Bewertung in Ökobilanzen. UBA Texte 92/99. ISSN 0722-186X. Berlin, Germany; 1999.

UBA-Umweltbundesamt. Umweltdaten Deutschland 2002. Umweltbundesamt und Statistisches Bundesamt. Berlin and Wiesbaden, Germany; 2002a.

UBA-Umweltbundsamt. Langfristszenarien für eine nachhaltige Energienutzung in Deutschland—Kurzfassung. Texte 02/02. Berlin, Germany; 2002b.

UBA-Umweltbundesamt. Umweltdaten Deutschland online. Berlin, Germany; 2005 [source: http://www.envit.de/umweltdaten/; 20 November 2005].

Weiss M. Flächenbezogener Vergleich von Umweltbelastungen durch Produkte auf Basis nachwachsender und fossiler Grundstoffe. Master thesis. TU Bergakademie Freiberg. Freiberg, Germany; 2004.

Weiss M, Patel M. On the environmental performance of bio-based energy, fuels, and materials-a comparative analysis of life cycle assessment studies. In: Miertus S, Graziani M, editors. Renewable resources and renewable energy: a global challenge. C.R.C. Press; in press.

Weiss M, Bringezu S, Heilmeier H. Energie, Kraftstoffe und Gebrauchsgüter aus Biomasse: Ein flächenbezogener Vergleich von Umweltbelastungen durch Produkte aus nachwachsenden und fossilen Rohstoffen. Zeitschrift für Angewandte Umweltforschung. Jahrgang 15/16. Heft 3-5; 2004. p. 361-78.

Wötzel K, Wirth R, Flake M. Life cycle studies on hemp fibre reinforced components and ABS for automotive parts. Die Angewandte Molekulare Chemie 1999;272:121-7.

Würdinger E, Roth U, Wegener A, Peche R, Rommel W, Kreibe S, et al. Kunststoffe aus nachwachsenden Rohstoffen: Vergleichende Ökobilanz für Loose-fill-Packmittel aus Stärke bzw. Polystyrol. Projektgemeinschaft BIfA/IFEU/Flo-Pak. Endbericht 2002 (DBU-Az. 04763). Institut für Energie und Umweltforschung Heidelberg; 2002 [source: http://www.ifeu.de; 29.07.2003]. 